\title{
CONCESSÕES DE SERVIÇO PÚBLICO DE ABASTECIMENTO DE ÁGUA AOS MUNICÍPIOS*
}

\begin{abstract}
ALICE GONZALEZ BORGES**
1. Premissas iniciais. 2. O abastecimento de água como parte do conceito de saneamento básico. 3. Tratamento constitucional da matéria. 4. Como explorar o serviço público de abastecimento de água? 5. Tratamento legal. Novas tendências. 6. Concessão de serviços de abastecimento de água, pelos Municípios, a empresas estaduais já existentes, estruturadas para sua prestação. Pontos polêmicos da legislação aplicável. 7. Reflexōes finais.
\end{abstract}

\section{Premissas iniciais}

Grandes e marcantes transformações econômicas, políticas e sociais operam-se no mundo de hoje. Constata-se uma verdadeira reviravolta e reconceituação do próprio papel do Estado contemporâneo: seja por força da globalização da economia, que se opera em todos os quadrantes; seja em decorrência da crise das concepções que, a pretexto da aplicação dos generosos princípios do Estado Social de Direito, vinham desenvolvendo o mais extremado e danoso intervencionismo estatal, anquilosante da iniciativa privada, sem, entretanto, resolverem os angustiantes problemas sociais de nossa época; seja, ainda, pela verdadeira crise de eficiência que defrontam as gestões estatais; seja, enfim, pelo fenômeno, propiciado pelo progresso da moderna tecnologia, do desenvolvimento de um novo conceito de cooperação e parceria entre os mais diversos setores, alcançando novos aspectos e dimensões

Defrontamos, portanto, no cenário nacional e internacional, profundas e complexas mudanças, que exigem do direito administrativo um constante repensar de

* Palestra proferida em Aracaju-SE, durante o XI ENCONTRO NACIONAL DOS ADVOGADOS DAS EMPRESAS DE SANEAMENTO BÁSICO, em 31 de julho de 1997.

** A autora é professora titular de Direito Administrativo da Faculdade de Direito da Universidade Católica de Salvador-Bahia e membro do Conselho Superior do Instituto Brasileiro de Direito Administrativo.

R. Dir. Adm.,

Rio de Janeiro, 212: 95-107,

abr./jun. 1998 
novas soluções, uma reavaliação de suas técnicas de desempenho, para que se compatibilizem com as novas concepções políticas, as realidades econômicas. os avanços da tecnologia e com as mais caras aspirações da sociedade.

Entre essas novas soluções, a intervenção excessiva, e, até, abusiva, do Estado na economia, que marcava os anos 70 , cede passo, cada vez mais, a diversas formas de parceria com a iniciativa privada.

Busca-se intensamente, com ou sem propósito, às vezes, até, de maneira bastante polêmica, a retirada da presença do Estado nos diversos setores de atividade econômica. Consequientemente, dentro da palavra de ordem da privatização e da desestatização, tem-se desenvolvido, sob as coordenadas da Lei no 8.131 e suas alterações posteriores, intenso esforço para a privatização das empresas estatais vocacionadas para a exploração de setores cada vez mais expressivos da atividade econômica strictu sensu, em regime de competição de mercado.

Orienta-se, mais, em um segundo momento, para a privatização das empresas estatais criadas exclusivamente para a prestação de serviços públicos - às quais se atribuíra, para fins operacionais, um regime híbrido, predominantemente sujeito ao direito privado, na tentativa, nem sempre bem-sucedida, de conferir-lhes maior flexibilidade de ação.

Por último, direciona-se o Estado para a impropriamente chamada "privatização" de serviços públicos.

Evidentemente, não se trata de privatização, pois é da essência conceitual desta a retirada total da presença do Estado de uma empresa ou atividade. Ao invés disso, o ordenamento jurídico brasileiro enumera, em sede constitucional, um elenco quase exaustivo de seus serviços públicos e lhes define expressamente os princípios vetores a que devem estrita obediência.

Não obstante a possível influência que possam ter, no particular, os exemplos e a própria nomenclatura do direito comparado (1), em nosso País essa pretendida "privatização de serviços públicos" não vai, e constitucionalmente não pode ir pelo menos, até a próxima emenda constitucional desfiguradora de nosso Texto Maior -, além das diversas formas de delegação da prestação de serviços públicos a particulares, sob a inafastável e indeclinável regulação, fiscalização e controle do Poder Público, o qual há de conservar, sempre, para todos os efeitos, por ser da essência mesma de toda delegação, a sua plena titularidade.

O que estamos vendo, na realidade atual, é, não a privatização propriamente dos serviços públicos, mas, sim, o ressurgimento e o reflorescimento, em novas bases, do antigo instituto da concessão de serviço público, que ganhou um novo e maior relevo em nosso direito atual, como forma de parceria possível entre o Poder Público e a iniciativa privada.

Para isto, contribuiu decisivamente a Constituição da República de 1988, definindo-lhe os delineamentos básicos e os princípios norteadores, no artigo 175 e seu parágrafo. Bem assim, o disciplinamento da matéria, em nível infraconstitucional, através das Leis nº 8.987 e 9.074, ambas do ano de 1995.

Podem, sem dúvida, apontar-se vários defeitos, omissões, incoerências e perplexidades, no tratamento legal que esses dois diplomas deram às concessões e permissōes de serviços públicos, resvalando-se. até. em frequientemente alegados 
vícios de inconstitucionalidade. Mas, no conjunto, exsurge a inevitável conclusão de que marcam uma nova era no disciplinamento da matéria.

É à luz dessas novas tendências e da nova disciplina, que teremos de examinar o palpitante tema que nos foi dado para a presente exposição.

\section{O abastecimento de água como parte do conceito de saneamento básico}

Nunca se falou tanto em saneamento básico neste País. O saneamento básico aparece como o objetivo central e inevitável das plataformas eleitorais. Ergue-se, a toda hora, a necessidade de uma política eficaz de saneamento básico, como verdadeira bandeira da redução da presença do Estado na economia, para que possa este dedicar-se mais plenamente a suas tarefas fundamentais. Educação, saúde e saneamento básico, apresentam-se, assim, como os verdadeiros objetivos essenciais em que deve concentrar-se a atuação do Estado.

$\mathrm{E}$, no entanto — dizem as estatísticas - , nunca foram tão gritantes as carências da população no setor de saneamento básico, com sérias e graves repercussōes na saúde pública em geral.

Recorremos, neste passo, ao conceito de saneamento básico do artigo $227 \mathrm{da}$ Constituição do Estado da Bahia:

"Todos têm direito aos serviços de saneamento básico, entendidos fundamentalmente como de saúde pública, compreendendo abastecimento de água, coleta e disposição adequada dos esgotos e do lixo, drenagem urbana de águas pluviais, controle de vetores transmissores de doenças e atividades relevantes para a promoção da qualidade de vida".

Fácil é, pois, concluir-se, que o abastecimento de água é serviço público, incluído no conceito maior e mais abrangente de saneamento básico.

\section{Tratamento constitucional da matéria}

Assim entendida, a matéria de saneamento básico, e, conseqüentemente, também de abastecimento de água e coleta e disposição de esgotos, tem sua competência amplamente prevista na Constituição.

Não se trata, como nos casos constantes dos incisos XI e XII do artigo 21, de matéria de competência titularizada apenas pela União, que a possa, entretanto, delegar a terceiros, através de concessão, permissão ou autorização. Sobre saneamento básico, limita-se a competência da União, nos precisos termos do art. 21, inc. $\mathrm{XX}$, apenas, à instituição de diretrizes básicas.

A matéria se insere entre os serviços de competência comum de todas as ordens federadas, no artigo 23, inciso IX, no que diz respeito à melhoria das condições de saneamento básico.

Para disciplinamento de uma ação conjunta e integrada da União, Estados, Distrito Federal e Municípios, em cooperação, para o atendimento dos setores de 
serviço que prevê, o parágrafo único desse mesmo artigo 23 exigiu uma lei complementar, que nunca foi editada até hoje.

Desenganadamente, ante o que dispõe a Constituição da República, situam-se os serviços de saneamento básico e abastecimento de água na órbita da competência própria dos Municípios, ainda que respeitadas as diretrizes federais previstas no art. 21 , inc. XX, da Constituição da República: isto, não somente por serem de interesse predominantemente local (art. 30, inc. II), como por caber aos Municípios, nos termos do art. 30 , inc. V, a competência para organização dos serviços públicos que thes são próprios, inclusive mediante concessão e permissão.

\section{Como explorar o serviço publico de abastecimento de água?}

Como visto, a decisão sobre a matéria compete primordialmente aos Municípios.

Tal decisão poderá ser adotada por quatro formas, igualmente admitidas em nosso direito:

a) através de exploração direta do serviço;

b) através da chamada prestação complexa ou associada, mediante a utilização de convênios ou dos chamados consórcios administrativos entre pessoas de direito público ou suas entidades públicas regidas pelo direito privado, pertencentes a outras esferas administrativas de competência. (2).

c) através da criação de entidades públicas descentralizadas, especificamente destinadas à exploração de serviços públicos comerciais ou industriais;

d) mediante delegação, através da concessão de serviços públicos, a particulares, a quem são transferidos os ônus e os riscos do empreendimento, mas não a titularidade do serviço.

\section{Tratamento legal. Novas tendências}

Podemos distinguir as tendências predominantes a respeito da solução do problema em dois períodos: antes da Constituição de 1988 e após a Constituição de 1988.

* Até o advento da Constituição de 1988, imperava a orientação federal sobre a matéria, consubstanciada na aplicação do PLANASA.

Incentivava-se, então, em todo o território nacional, a criação de companhias estaduais para a prestação de serviços de abastecimento de água, e a estas era confiada a tarefa de executarem os objetivos daquele Plano.

Ou realizavam-se convênios entre as municipalidades e os Estados para a prestação desses serviços, tendo como órgão executor a companhia estadual criada com essa finalidade.

Ou, então, efetuavam-se "concessões" de serviço público, nas quais figurava o Município como concedente, e, como concesssionária, a companhia estadual. Mas, 
ressalte-se, tais concessões eram estruturadas à vontade, por falta de um disciplinamento legal específico, apenas seguindo-se a aplicação das lições da doutrina.

Hoje, a tendência governamental predominante se dirige no sentido da privatização das companhias estatais prestadoras do serviço público, e no da concessão do serviço de abastecimento de água a empresas particulares.

Mas remanesceu, não resolvida, a problemática criada por certos aspectos da realidade prática precedente.

De um lado, por algum motivo subsistem, ainda, empresas estaduais criadas exclusivamente para a prestação daqueles serviços, algumas, aliás, em vias de pretendida privatização. De outro lado, dispomos, em sede do direito positivo, de um disciplinamento legal efetivo das concessões de serviços públicos, mas este foi nitidamente direcionado para reger as relações do poder público com empresas particulares.

Cresce de ponto o problema, na medida em que os Municípios, ainda quando disponham de competência constitucionalmente induvidosa para disciplinar e organizar tais serviços, nem sempre possuem, efetivamente, mananciais de água próprios.

Ora, nesse particular, cumpre ressaltar que são os Estados os únicos competentes para a disciplina legiferante acerca dos seus próprios bens, e, entre esses bens, se incluem certamente os seus próprios recursos hídricos (art. 26, inciso I - CF). Ocorrem, pois, inevitáveis interferências de competência no disciplinamento da espécie.

\section{Concessão de serviços de abastecimento de água, pelos municípios, a} empresas estaduais já existentes, estruturadas para sua prestação. Pontos polêmicos da legislação aplicável

1. Com as novas regras constitucionais que passaram a reger a prestação dos serviços públicos; com o advento da nova legislação de concessões; e com a tendência generalizada para a desestatização da prestação de tais serviços através de sua delegação a empresas particulares, criaram-se vários pontos polêmicos em torno da legislação aplicável às relações jurídicas entre os Municípios e as empresas estaduais prestadoras de serviço público de abastecimento de água.

São outras tantas indagações, que ensejam respostas profundamente divergentes na doutrina. Vejamos as principais.

$1^{\text {a }}$ - As empresas estaduais prestadoras de serviços de abastecimento de água estão obrigadas a entrar em licitação para contratarem com os Municípios a concessão desses serviços?

Segundo uma respeitável corrente doutrinária, aplicar-se-ia, no caso, o disposto no artigo 24, VIII, da Lei 8.666/93, que contempla uma hipótese de dispensa de licitação. Mas tal hipótese vigoraria somente para as empresas já constituídas até a vigência da referida Lei; é que o citado dispositivo funcionaria como uma espécie de regra transitória, para resguardá-las da obrigatoriedade de licitar.

Segundo outros, tratar-se-ia, em relação a tais empresas, de aplicabilidade do artigo 25 , caput, quando prevê a inexigibilidade da licitação por inviabilidade de 
competição. A esse respeito, são clássicas as lições de ADILSON DALLARI, que vê, na hipótese, um dos casos de impossibilidade jurídica da licitação. (3).

Segundo outros, como CELSO ANTONIO BANDEIRA DE MELLO (4), o citado artigo 24, inciso VIII, da Lei no 8.666/93, não se aplica aos contratos que têm por objeto a gestão de serviços públicos, porque estes, disciplinados pela Lei $n^{Q}$ $8.987 / 95$, que lhe é posterior, "dependem da disputa efetuada na intimidade do competente procedimento licitatório".

Vencida que seja a polêmica, surge novo impasse.

$2^{\mathrm{a}}$ - Não podem as empresas estaduais prestadoras de serviços de abastecimento de água concorrer às licitações com recursos oriundos da pessoa pública sua controladora?

Enquanto a Lei $n^{2} 8.666 / 93$ veda, expressa e severamente, o auto-financiamento do empreendimento pelos licitantes (artigo 7ㅇ, $\S 3^{\circ}$ ) , sob pena de nulidade (art. 70, $\S 6^{2}$ ), salvo nos casos de concessão, a Lei $n^{\circ} 8.987 / 95$ prevê, taxativamente, como encargo da concessionária, no art. 31 , inc. VIII,

"captar, aplicar e gerir os recursos financeiros necessários à prestação do serviço".

Mas, no artigo 17, parágrafo único, a mesma Lei 8.987/95 dispõe que:

"considerar se-á, também, desclassificada a proposta de entidade estatal alheia à esfera político-administrativa do poder concedente que, para sua viabilização, necessite de vantagens ou subsídios do poder público controlador da referida entidade".

A interpretação do dispositivo leva a duas conclusões, por via de conseqüência:

1a- a lei 8.987/93 admite e não dispensa, em princípio, que concorra, à licitação para concessões, entidade estatal alheia à esfera político-administrativa do poder concedente;

$2^{\mathrm{a}}$ - qualquer empresa particular pode concorrer à licitação para concessão de serviços públicos, captando recursos financeiros de terceiros. Mas a entidade estatal de esfera político-administrativa diversa da do poder concedente não pode contar, sob pena de sumária desclassificação, com quaisquer vantagens ou subsídios da pessoa política sua controladora.

Qual a lógica desse tratamento contraditório e discriminatório? Só há uma conclusão possível: a de que o legislador, em seu afã privatizador, pretendeu desestimular, praticamente, que tais empresas estaduais competissem com as empresas particulares nas licitações para concessão de serviços públicos. (5)

Pois, evidentemente, se um Estado cria suas sociedades de economia mista, com capital público votante majoritário, ou suas empresas públicas, com participação total de capital público, de qualquer sorte terá, mesmo, de subsidiá-las com ponderável parcela de seus recursos, sobretudo para que possam atender à finalidade precípua determinada pela lei de sua criação.

Dizer-se que, assim competindo, a empresa estaria agindo como concorrente desleal, em desobediência aos preceitos do art. 173 da Constituição, prova demais: pois, então, mais desleal ainda seria a concorrência de empresas privadas que podem captar recursos financeiros de terceiros, tanto mais que agora até já se anuncia a modificação da política das entidades internacionais, como o BIRD, para admitir 
que, através do FIC, possam as mesmas financiar empresas particulares para certos investimentos de interesse público.

33. $O$ art. 42, $\S 5 "$, da Lei $n^{\circ} 8.987 / 95$ mantêm vigentes, por um prazo de 24 meses - que já se esgotou -, as anteriores concessões de serviços públicos, com prazo vencido ou em vigor por prazo indeterminado, isto é, até 13/02/97, e declara extintas as concessões que foram outorgadas sem licitação na vigência da Constituição de 1988. Não faz nenhuma exceção a tal regra. Como ficam, então, as concessões de serviço público efetuadas anteriormente pelos Municípios a empresas estaduais de abastecimento de água?

A decisão a respeito do assunto não pode ser imposta pelo legislador federal, por que se trata de matéria pertinente à autonomia organizacional-administrativa dos Municípios para gerir seus próprios serviços.

A questão, aliás, envolve, por sua vez, duas outras indagações, a respeito da temática das empresas estaduais de saneamento "concessionárias" de serviços públicos municipais:

1a se a Lei $\mathrm{n}^{\mathrm{Q}} 8.987 / 95$ seria cogente para os Estados e Municípios, e

$2^{\mathrm{a}}$, se é aplicável, para estes últimos, a regra do art. $2^{\circ}$ da Lei $\mathrm{n}^{\circ}$ 9.074/95.

Tem razão de ser a discussão. Afinal, trata-se, no caso em estudo, de serviços públicos, e de serviços públicos que não são da competência privativa da União, como aqueles previstos no art. 21 , incisos XI e XII da Constituição da República.

Em matéria de organização dos próprios serviços públicos, vigora plenamente a regra constitucional da autonomia organizacional-administrativa das ordens federadas, estabelecida no art. 18, CF. Então, há quem sustente que o legislador federal não poderia, constitucionalmente, impor suas regras aos Estados e Municípios.

No que diz respeito à lei $8.987 / 95$, a questão tem outros desdobramentos.

Partindo-se de que a Constituição tratou, induvidosamente, como contratos, as concessões e até as permissões de serviços públicos, no artigo 175, e que a mesma Constituição atribuiu ao legislador federal a competência para dispor sobre normas gerais de licitações e contratos administrativos, parece lógica a conclusão de que, em princípio, a União pode, efetivamente, dispor sobre normas gerais pertinentes ao conteúdo do regime jurídico dos contratos de concessão, como o fez na Lei $\mathrm{n}^{\mathrm{a}}$ $8.987 / 95$, bem como as normas concernentes a suas licitações.

Determinar, entretanto, quando suas concessões se extinguem, ou até quando são prorrogáveis, já é matéria da exclusiva competência de cada ordem federada, no uso de sua autonomia constitucionalmente assegurada.

Já a Lei $n^{2} 9.074 / 95$ tratou, em sua maior parte, do disciplinamento de matérias pertinentes à concessão de serviços públicos que são da competência privativa federal, excetuados, pela sua especificidade própria, os de telecomunicações.

Destoa, pois, a regra do artigo $2^{o}$, que pretende impor, à autonomia das ordens federadas, a obrigação de não executarem obras ou serviços públicos mediante concessão ou permissão, sem lei que a autorize.

Esse artigo é nitidamente inconstitucional. Se pode a União estabelecer normas gerais sobre o conteúdo das contratações de concessão de serviço público e suas licitações, não pode, entretanto, impor aos Estados, Distrito Federal e aos Municípios 
que expeçam, ou não, lei para autorizá-las. Já aí, configura-se interferência na sua própria atividade legiferante, o que viola frontalmente o artigo 18, da Constituição.

Aliás, é o próprio dispositivo legal federal, em comento, o primeiro a excepcionar essa exigência de prévia e específica autorização legal, em casos de saneamento básico e limpeza urbana. (6)

\section{Reflexões finais}

1. As indagações polêmicas trazidas a discussão, as perplexidades surgidas na interpretação e aplicação da legislação específica das concesssões, têm como origem, a nosso ver, uma condução originariamente equivocada do problema posto.

$O$ legislador federal tem duas manias: uma, a de legislar intermitentemente, aos trancos, com casuísmo, sem a menor preocupação de adaptar as novas normas ao ordenamento jurídico já existente, bem como a de conhecê-lo e preservá-lo; outra, a de legislar sem a mínima cautela de procurar conhecer, de antemão, as realidades de um país tão diversificado como o nosso; ignorando, enfim, que nosso território abriga, em realidade, muitos Brasis.

Há municípios e municípios, por este Brasil afora.

Há aqueles que podem enfrentar, com vantagem, a decisão de explorar seus serviços de abastecimento de água, delegando-os a grandes empresas privadas, ou, como já vem ocorrendo, a consórcios de que participem empresas estrangeiras de grande porte, detentoras da mais sofisticada tecnologia, que até consigam financiamentos de órgãos internacionais. Para estes, vale recorrerem à aplicação das disposições da Lei $\mathrm{n}^{\circ} 8.987 / 95$, que, aliás, foram editadas para isso.

Mas há os que não o podem, mesmo. Ou porque não têm recursos financeiros suficientes, sequer, para pagar sua própria folha de pessoal; ou porque a rentabilidade dos seus serviços de abastecimento de água, se houver alguma rentabilidade, não é suficiente para atrair investidores privados.

Há - infelizmente é verdade - aqueles municípios que nem saberiam como começar o complexo e sofisticado procedimento que a Lei $8.987 / 95$ impõe à outorga das concessões, procedimento, esse, concebido evidentemente, em seus delineamentos, para grandes investimentos e grandes empresas.

E, se o começarem, não têm a mínima condição de efetivar a fiscalização das concessões, que é seu dever indeclinável, inclusive, como a lei prevê, pelo exame da escrituração contábil das empresas privadas, ou pela própria intervenção na gestão do serviço pela concessionária.

São essas, em resumo, apenas algumas das questões polêmicas que o tema suscita, e que causam não poucas perplexidades às empresas estaduais de saneamento.

2. Calou-nos fundo, e a absorvemos integralmente, a oportuna e patriótica advertência do jovem administrativista JUAREZ FREITAS, no sentido de que o que interessa à sociedade brasileira não é o Estado Máximo, nem o Estado Mínimo, mas, muito simplesmente, o ESTADO ESSENCIAL, que possa atender às necessidades coletivas das maneiras mais hábeis, construtivas, flexíveis e eficientes, sim, mas sem 
nunca abdicar de suas indeclináveis responsabilidades para com o povo cujos interesses representa.

Recorrerem os municípios às empresas estaduais concessionárias dos serviços de abastecimento de água, é prática largamente generalizada em todo o País, que não pode ser ignorada, e que, certamente, não se deveu, tão-somente, à imposição, já superada dos objetivos do PLANASA, mas sim, em grande parte, por ser a solução mais viável para certas municipalidades.

Mas - e este é o ponto nuclear de toda a questão - essas empresas estaduais criadas para os serviços de abastecimento de água não são, nunca foram, nem poderão ser, verdadeiras concessionárias de serviço municipal - o que, aliás, mesmo no passado, mesmo antes do advento da Lei $8.987 / 95$, sempre nos pareceu verdadeira distorção dos princípios essenciais de nosso ordenamento jurídico.

E não o podem, porque a relação jurídica que se estabelece, neste caso, figurando em um de seus polos, a empresa descentralizada pelos Estados, criada exclusivamente para a prestação de serviços públicos; e, no outro, a pessoa jurídica pública do Município, é, em tudo e por tudo, não uma relação jurídica bilateral, com o estabelecimento de vínculo, com prestações e contraprestações recíprocas, no atendimento de interesses opostos, como tenta definir o artigo $2^{\circ}$ da Lei 8.666/95; mas, sim, nitidamente uma relação jurídica multilateral, em que pessoas e entidades públicas se associam para conjugar seus esforços no atendimento de um interesse coletivo comum. É a lição de JOSÉ DE ABREU FILHO (7).

Trata-se da associação de pessoas públicas, conjugando seus recursos ou suas possibilidades concretas de angariarem recursos, com outras entidades também públicas, de outra esfera administrativa - como, no caso, empresas públicas ou sociedades de economia mista estaduais - mas em outro nível, mais apropriado, qual seja o da prestação associada de serviços, em regime de estreita cooperação, para o atingimento do interesse comum, como previu o constituinte no parágrafo único do art. 23 do Texto Maior.

Colocamo-nos, pois, inteiramente de acordo com ALAOR CAFFÉ, quando defende a aplicação, a essas realidades concretas, do disposto no parágrafo único do art. 23 da Constituição da República. (8)

Louvavelmente, aliás, passando da teoria à prática, esse notável jurista pátrio já elaborou e trouxe a este conclave um anteprojeto da lei complementar prevista pelo constituinte, disciplinadora da prestação associada ou complexa de serviços públicos, entre diversas pessoas e entidades públicas, pertencentes a órbitas federadas distintas.

3. Ora, se parte da inevitável premissa inicial de que empresas estaduais de saneamento não podem ter o mesmo tratamento das demais concessionárias de serviço público municipal, tudo se esclarece.

Desaparecem aquelas perplexidades em torno da aplicação da Lei $\mathrm{n}^{\circ} \mathbf{8 . 9 8 7 / 9 5}$, pelo reconhecimento da evidência de que estoutra lei foi elaborada para disciplinar outra espécie de relação jurídica, qual seja o vínculo contratual que se estabelece entre o poder público e empresas particulares.

Não podem ter qualquer aplicação à espécie, nem as hipóteses de dispensa, nem as de inexigibilidade de licitação. Muito simplesmente, as relações entre pessoas 
públicas e entidades públicas de unidades federadas diversas se desenvolvem em outro plano. um plano superior, em que não cabe qualquer espécie de competição, e, sim, uma associação, em prol da consecução de objetivos e competências comuns.

Certas referências que se captam, aqui e ali, nas Leis no 8.987/95 e 9.074/95, as quais possam conduzir a entendimento diverso, ou são inconstitucionais, ou completamente inaplicáveis à espécie concreta que ora estudamos.

O mesmo pode-se dizer quanto ao próprio conteúdo do contrato de concessão, se aplicado às relações jurídicas entre pessoas ou entidades de órbitas distintas da Federação, porque certamente vai ter repercussões políticas indesejáveis sobre o próprio pacto federativo.

É difícil imaginar-se, por exemplo, um município fiscalizando, mas fiscalizando mesmo, para valer, uma entidade pública estadual, tal como determina a lei de concessões de serviços públicos. Os governantes estaduais dispõem de vários recursos de pressão política para escaparem a esse tipo de controle. O que irá ocorrer, na prática, será a pseudocontrolada passar a governar a pseudocontrolante.

Em outra dimensão, prevê a Lei 8.987/95 o uso, pelo poder concedente, de várias prerrogativas de potestade pública, em relação a suas concessionárias, tais como a da alterabilidade unilateral dos contratos, a sua rescisão unilateral antecipada e a aplicação de penalidades. Não há como dissociar-se a questão, na prática, de suas conotações políticas, tornando inviável a aplicação dessas prerrogativas pelo Município em relação ao Estado, ou às suas entidades descentralizadas.

Há outras implicações políticas. Se a Lei $8.987 / 95$ prevê a intervenção do poder concedente, como forma institucionalizada de controle extraordinário sobre as atividades da concessionária, tal se torna inviável, no caso, porque fatalmente irá repercutir sobre as relações políticas entre estado e município. O mesmo poderá dizer-se em relação à encampação e à caducidade, bem como às suas consequiências indenizatórias, todas concebidas, na lei, para que o particular se recupere dos investimentos realizados por sua própria conta e risco. Bem assim, a preservação do equilíbrio econômico-financeiro inicialmente ajustado pela proporcionalidade entre os encargos e a remuneração da concessionária, esta última abrangendo a constitucionalmente legítima expectativa de lucro, inconcebível, entretanto, em relação a uma entidade pública criada para a prestação de serviço público. $\mathrm{E}$ assim por diante. É realmente infindável a lista dos absurdos jurídico-institucionais que desfilam ante nossos olhos, ante a tentativa de aplicar-se, às relações entre pessoas e entidades públicas de esferas de competência diversas, um molde jurídico que, evidentemente, não lhes serve (9).

4. Se o município dispõe das condições indispensáveis e apropriadas, que recorra, através de licitação, ao instituto da concessão do serviço público a empresas particulares, com integral aplicação da disciplina da legislação própria.

Mas, se não dispõe delas, terá que partir para a cooperação com outras pessoas ou entidades públicas. Mesmo assim, o profundo interrelacionamento entre os interesses públicos a serem envolvidos na questão enseja certa ordem de considerações, que tornam única, para cada caso concreto, a solução a ser adotada.

Se o município dispõe de mananciais próprios, certamente terá maior possibi- 
lidade de enfrentar o problema com maior autonomia. Mas, em grande número de casos, não existe tal disponibilidade.

Se enfrentamos a problemática de vários municípios interligados, dispondo de mananciais comuns a todos eles, será talvez o caso de enfrentar-se a solução do problema através da constituição de consórcios administrativos intermunicipais, desde que haja condições políticas para tanto.

Há que verificar-se, ainda, se os municípios, além de interligados pela utilização de mananciais comuns, pertencem à mesma região metropolitana, pois então desloca-se a solução para a competência predominante do Estado em que está situada essa região metropolitana, nos termos do que dispõe o artigo $25, \S 3^{\circ}$, "para integrar a organização, o planejamento e a execução de funções públicas de interesse comum".

Há, ainda, que levar-se em conta, sempre, a inevitável interferência da solução dos problemas locais de abastecimento de água com o desenvolvimento dos planos estaduais disciplinadores da utilização dos seus recursos hídricos dos Estados.

As diversas problemáticas que temos a enfrentar, no caso, encontram suas soluções ou, provisoriamente, na celebração de convênios ou consórcios administrativos - conforme o caso; ou, de modo definitivo, na estruturação legal, que já tarda, da cooperação sistemática das unidades federadas e de suas entidades descentralizadas, associadas em torno da prestação de serviços que são da competência e do interesse de cada uma delas e de todas, ao mesmo tempo.

Enfim, inexiste uma solução única para todos os problemas enfrentados na realidade prática, ante necessidade coletiva tão importante, prioritária e vital.

Se é dos Municípios, fundamentalmente, a decisão sobre como explorarão os serviços públicos de abastecimento de água e de esgotos, é o interesse público das grandes populações de baixa renda, desprovidas das mínimas condições de higiene e salubridade, que deverá afinal prevalecer sobre essa decisão, para que se consiga a solução ótima. E a solução ótima, ressalve-se, há de ser, unicamente, a ótima para a coletividade.

\section{NOTAS}

(1) Vide, por exemplo, a notável obra do jurista espanhol VILLAR ROJAS, intitulada "Privatización de Servicios Públicos", de grande trânsito entre nós (Madrid, Editorial TECNOS, 1993).

(2) DIOGO FIGUEIREDO MOREIRA NETTO ("Constituição e Revisão", Rio de Janeiro, Forense, 1991, p. 177, nota de rodapé no 6) e MARÇAL JUSTEN FILHO (“Concessões de Serviços Públicos", São Paulo, Dialética, 1997, p. 74), coincidem no entendimento de que o silêncio da atual Constituição sobre a figura do convênio entre entidades públicas, prevista no art. $13, \S 3^{\circ} \mathrm{da}$ Carta anterior (denominado, por DIOGO FIGUEIREDO MOREIRA NETTO, de ato administrativo complexo interfederativo, juntamente com os consórcios administrativos, e anunciado como tendência para o federalismo regional) não implica em sua vedação, pois a autonomia recíproca dos entes federados, estatuída no artigo 18 da Constituição, não impede a 
conjugaçāo de esforços para multiplicar os recursos necessários à satisfação dos interesses públicos. É certo que. como ainda salienta este último autor, em definitivo " as normas de cooperação interfederativa deverão ser fixadas em lei complementar (art. 23, parágrafo único).

(3) "Órgãos e entidades públicas não concorrem entre si. Quando o Poder Público cria uma entidade para servir como instrumento de sua atuação, é como se fosse o próprio Estado "contratando" consigo mesmo, ainda que se trate de relação entre entidades de diferentes pessoas jurídicas de capacidade política" ("Aspectos jurídicos da licitação", São Paulo, Editora, Saraiva, 1997, p. 60, citando, em seu apoio, DROMI, "Licitación Pública", Buenos Aires, Ediciones Ciudad Argentina, 1995, p. 154).

(4) Parecer datado de 28 de abril de 1997, exarado em atendimento a consulta específica da Associação Brasileira das Concessionárias de Serviços Públicos de Água e Esgoto - ABCON, e que foi distribuído ao plenário do XI ENCONTRO NACIONAL DOS ADVOGADOS DAS EMPRESAS DE SANEAMENTO BÁSI$\mathrm{CO}$

(5) Por feliz coincidência, também CARLOS PINTO COELHO MOTTA pensa assim. ("Eficácia nas licitações e contratos", Belo Horizonte, DEL REY, 1997, 6ª edição, p. 540.

(6) Cf. ARNOLDO WALD et allii, "O Direito de Parceria e a Nova lei de Concessões", São Paulo, Editora Revista dos Tribunais, 1996, p.178).

(7) JOSÉ ABREU FILHO distingue, em sua obra, com apoio na doutrina de BETTI e VON TUHR, os contratos dos negócios jurídicos plurilaterais, que denomina de acordos: nestes últimos, existem interesses paralelos ou convergentes para um escopo comum, destinando-se, pois, a adotar decisões comuns em assuntos de interesse coletivo. ("O Negócio Jurídico e sua Teoria Geral", São Paulo, Editora Saraiva, 1995, $3^{a}$ edição, pp. 75 e seguintes.)

(8) Parecer elaborado em atendimento em consulta da SABESP (Companhia de Saneamento Básico do Estado de São Paulo, datado de 15 de maio de 1996, distribuído por cópia ao XI ENCONTRO NACIONAL DOS ADVOGADOS DAS EMPRESAS DE SANEAMENTO BÁSICO.

(9) A propósito, em antigo acórdão do Tribunal de Justiça do Estado de Minas Gerais, publicado na Revista de Direito Público, vol. 26, p. 152, decidiu-se que "é ilegal o ato do Prefeito de Itajubá declarando caduco o contrato de concessão celebrado entre a Prefeitura e a COMAG, sociedade de economia mista, para a concessionária executar e explorar serviços de abastecimento de água", justificando-se que "não se pode legitimar a caducidade do contrato de concessão de serviço público com prazo certo, nem sua rescisão por ato unilateral, quando o mesmo venha a ser avençado entre um Poder Público e outro, pois aplicar, em tal situação, o "jus imperium", seria entrar em antagonismo, com menoscabo ainda ao princípio do federalismo cooperativo".

MARÇAL JUSTEN FILHO, em obra recente, ocupa-se lucidamente deste assunto, classificando tal espécie de ajuste como "concessão-convênio", e concluindo que:

"O princípio da Federação impede a aplicação das regras peculiares à concessão. Não se poderia admitir que um Município, concedente de serviço público a uma 
empresa pública federal, promovesse intervenção na entidade. O exercício desse poder seria inerente ao contrato de concessão, mas representaria forma indireta de intervenção do Município na União, incompatível com a Constituição. O mesmo se daria relativamente a todas as hipóteses de relacionamento entre entes federais. $\mathrm{O}$ vínculo de concessão é juridicamente impossível entre entidades federais de órbitas distintas, por importar poderes incompatíveis com a autonomia de cada partícipe do pacto federativo". ("Concessōes de Serviços Públicos”, São Paulo, Dialética, 1997, p. 76.) 


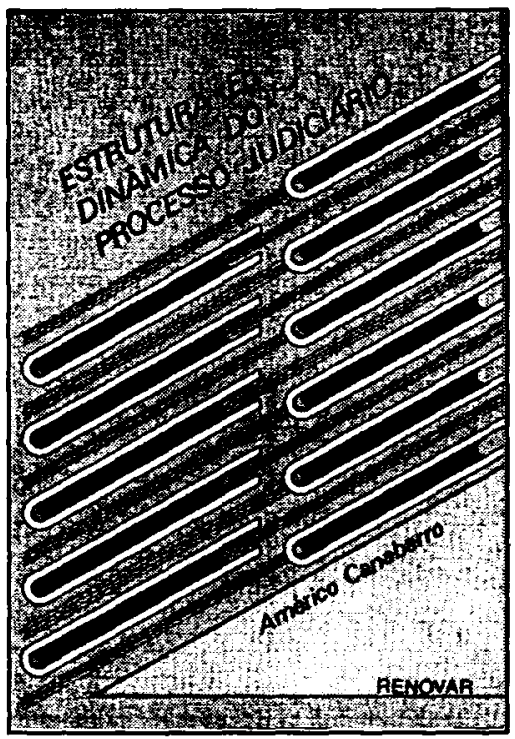

Ref. 0004

Brochura

180 págs.

Form. 14x21

1997

\section{ESTRUTURA E \\ DINÂMICA DO \\ PROCESSO \\ JUDICIÁRIO}

\section{Américo Canabarro}

Trata-se de um livro-guia que tem como finalidade orientar o estudante de Processo sendo também de grande utilidade para o profissional de Direito. $O$ autor analisa a estrutura e a dinâmica do processo, mostrando o fenômeno da sua formação e acompanha seu desenvolvimento até a finalização. 